Article

\title{
Dietary supplementation effects of the levels of Neem (Azadirachta indica) leaf extracts as phytogenic feed additive on the growth performance in broiler chicks
}

\author{
Shuvendu Sarkar ${ }^{\text {* }}$, Moniruzzaman Tarafder ${ }^{2}$, Md. Hafizur Rahman ${ }^{1}$, Moinul Khandaker $^{3}$, Golam Sagir \\ Ahammad $^{4}$, Dipok Kumar Sarker ${ }^{1}$, Bimal Chandra Karmakar ${ }^{5}$ and Beathy Islam ${ }^{6}$ \\ ${ }^{1}$ Department of Livestock Services, Ministry of Fisheries and Livestock, Government of the People's Republic \\ of Bangladesh \\ ${ }^{2}$ Scientific Officer, Rinderpest Vaccine Section, Livestock Research Institute, Dhaka, Bangladesh \\ ${ }^{3}$ Officer, Chattogram Breeder Farm-2, CP Bangladesh Co. Ltd \\ ${ }^{4}$ Bangladesh Institute of Research and Training on Applied Nutrition (BIRTAN), Ministry of Agriculture, \\ Government of the People's Republic of Bangladesh \\ ${ }^{5}$ Agriculture and Environment Division, Bangladesh Academy for Rural Development (BARD), Cumilla, \\ Bangladesh \\ ${ }^{6}$ Director, Grameen Jano Unnayan Sangstha, Bhola, Bangladesh
}

*Corresponding author: Shuvendu Sarkar, Department of Livestock Services, Ministry of Fisheries and Livestock, Bangladesh. E-mail: shovan058@gmail.com

Received: 01 March 2021/Accepted: 21 March 2021/ Published: 31 March 2021

\begin{abstract}
The effects that Neem leaf extract on overall growth, feed conversion ratio (FCR), dressed weight and organs weight of broiler chickens to justify its inclusion in the diet of growing broiler chickens. 120 day old chicks divided into four treatment groups T1, T2, T3 and T4 of thirty (30) birds each were administered clean drinking water with $3 \mathrm{gm}, 4 \mathrm{gm}, 5 \mathrm{gm}$ and $0 \mathrm{~g}$ neem extract respectively. Impacts of neem extract treatments on growth indices suggested that Neem extract favored growth with final body weight range of $1709 \mathrm{gm}$ and $1763 \mathrm{gm}$. Organ weights showed no deviation from standard values for healthy broiler birds. Highest growth was observed in group T3 $(1763.6 \pm 141.37 \mathrm{gm})$ followed by T1, T2 and lowest was in T4 group $(1565.4 \pm 161.25 \mathrm{gm})$. Birds on $5 \mathrm{gm}$ of Neem extract in their drinking water out performed birds in other treatments in assessed growth rate indices. We therefore conclude that $5 \mathrm{gm}$ of Neem extract in their drinking water growing broiler birds encourages healthy growth and may serve as supplements for antibiotics, especially when birds are raised in areas with minimal access to veterinary service.
\end{abstract}

Keywords: Azadirachta indica; broiler; growth performance; neem leaf extracts

\section{Introduction}

The production of healthy birds with quality meat and eggs without harmful residues, within a short time interval is the major concern to modern poultry farmers. The use of synthetic drugs as antibiotics and growth promoters has high cost implications, and sometimes, with attending adverse side effect on birds health, prolonged withdrawal period and risk of accumulation in tissues and egg which could have harmful effects on human health (Jawad et al., 2014; Sarker et al., 2018). As a result, consumers of poultry products are demanding for drug residues free meat and egg (Talukder et al., 2017). This has triggered the search for alternatives means to produce birds at reduced cost using natural growth and health promoters (Sarker et al., 2020).

So, researchers are now concentrating efforts on the use of ancient medicinal system to find beneficial herbs and plants, which can be safely used to increase production. Medicinal plants are cheap and renewable sources of pharmacologically active substances and are known to produce certain chemicals that are naturally toxic to bacteria (Islam et al., 2018). 
Herbs and spices have always been helpful to cure diseases. In modern animal feeding, they are forgotten because of use of antibiotic growth promoters (AGP). But due to the prohibition of most of AGP, plant extracts have gained interest in animal feed strategies (Noman et al., 2015). The risk of the presence of antibiotic residues in milk and meat and their harmful effects on human health have led to their prohibition for use in animal feed in the European Union (Cardozo et al., 2004). Generally, plant extracts have no problem of drug resistance. Herbs normally used are picorhiza, garlic, cloves, slippery elm, neem fruit and leaves, sophora flavescens, nutmeg, cinnamon, ginger, peppermint, sage, thyme, mustard and fenugreek. These plants are used as digestive stimulants, antidiarrhoic, antiseptic, antiinflammatory, antiparasitic and appetite stimulants in human beings as well as animals (Agarwal, 2002).

Herbal plants are traditionally used in therapeutic treatment for centuries. Natural medicinal products from herbs and spices have also been introduced as feed additives in poultry diets (Guo, 2003).

Neem (Azadirachta indica) tree in totality has been a village dispensary and a qualified plant by itself. Neem leaf and its constituents have been demonstrated to exhibit immunomodulatory, anti-inflammatory, antihyperglycemic, anti-ulcer, anit-malarial, anti-fungal and antihelmentic, antioxidant, antimutagenic and anticarcinogenic properties (Agarwal, 2002; Subapriya and Nagini, 2005; Paul et al., 2020). Some bioactive components of neem leaf are azadirachtin, meliantriol, nimbin, nimbidin, and salanin. Nimbin and nimbidin have been found to have antiviral activity.

Therefore, this research was performed to evaluate the effects of Neem Leaf Extract (NLE) as a growth enhancer in broiler diets.

\section{Materials and Methods}

\subsection{Experimental bird}

A total of one hundred and twenty (120) day old chicks (Cobb 500) were bought, on arrival, the chicks were counted, de-boxed, weighed. The chicks were brooded and acclimatized for one week, during which they were fed with commercial chick starter feed and cool clean drinking water.

\subsection{Experimental design}

At arrival of the birds, they were housed in the brooding house that had been prepared by cleaning, washing and disinfecting. Brooders were set up in good working condition. The floor was well littered with wood shavings and the walls covered with dark water-proof materials. At the completion of the brooding period, the birds were divided into four (4) major groups tagged T1, T2, T3 and T4 of thirty (30) birds each. Treatment 4 (T4) was the control and the birds in the T4 were administered clean drinking water without neem extract ( $0 \%$ neem extract). Treatments 1, 2 and 3 (T1, T2 and T3) were administered neem extracts (NE) at different concentrations of $3 \mathrm{gm}, 4 \mathrm{gm}$ and $5 \mathrm{gm}$ per liter of water respectively.

\subsection{Collection of neem leaves and preparation of fresh neem extract}

Mature disease free neem leaves were collected. $3 \mathrm{gm}$ for T1, $4 \mathrm{gm}$ for T2 and $5 \mathrm{gm}$ for T3 of neem leaves were weighed, washed blended with one (1) litre of water and with a sieve the leaf particles were removed for each treatment. For every quantity of drinking water measured, one (1) litre of neem extract was added and administered to the bird's upto 35 days. The, neem extracts was prepared on daily basis.

\subsection{Data collection and recording}

At the end of the experimental period, five (5) birds per treatment were randomly selected and bled by severing the jugular vein. Vital organs (Gizzards, lungs, liver, spleen, kidney, proventriculus, crop and heart) of the slaughtered birds were weighed using electronic weighing machine and records were taken for organ weight determination.

\subsection{Data analysis}

The data were analyzed statistically between the control and the treatment groups of chickens, between replicates of treatment and between treatment by variance (ANOVA) and means were compared employing Duncan's Multiple Range Test by SPSS IBM 20.

\section{Results and Discussion}

In this research we evaluate the effects that neem leaf extract on growth performance and organs weight of broiler chickens to justify its inclusion in the diet of growing broiler chickens. 120 day old chicks divided into 
four treatment groups T1, T2, T3 and T4 of thirty (30) birds each were administered clean drinking water with $3 \mathrm{gm}, 4 \mathrm{gm}, 5 \mathrm{gm}$ and $0 \mathrm{gm}$ neem extract respectively.

The effects of feeding different concentration of dietary neem on daily body weight gain are shown in Table 1. All groups had initial body weight $91.32 \pm 0.78 \mathrm{gm}$. No mortality was detected in all treatment groups throughout the study period. Feed Conversion Ratio (FCR) is shown in Table 2, where significant variation was evident in $\mathrm{T}_{1}$. Dressed weights of birds are shown in Table 3. No significance variation was found in offal's weight (Table 4).

\subsection{Growth performance}

Daily body weight gain was collected in record log book. In Table 1, average weight gain from day 7 to day 35 is shown with 7 days interval. Best weight gained was observed in $T_{3}$ group at day 35 followed by $T_{1}, T_{2}$ and lowest in $\mathrm{T}_{4}$.

Table 1. Live body weight of birds from day 7 to day 35.

\begin{tabular}{llllll}
\hline \multirow{2}{*}{ Groups } & \multicolumn{5}{c}{ Body weight gain $(\mathbf{g m})$} \\
\cline { 2 - 6 } & Day 7 & Day 14 & Day 21 & Day 28 & Day 35 \\
\hline $\mathbf{T}_{\mathbf{1}}$ & $90.4 \pm 4.07^{\mathrm{a}}$ & $310.5 \pm 22.82^{\mathrm{a}}$ & $704.2 \pm 45.22^{\mathrm{ab}}$ & $1330.5 \pm 72.34^{\mathrm{b}}$ & $1754.3 \pm 109.34^{\mathrm{a}}$ \\
$\mathbf{T}_{\mathbf{2}}$ & $91.5 \pm 6.01^{\mathrm{a}}$ & $331.5 \pm 21.93^{\mathrm{a}}$ & $710.2 \pm 51.20^{\mathrm{ab}}$ & $1327.2 \pm 85.46^{\mathrm{ab}}$ & $1709.2 \pm 119.47^{\mathrm{a}}$ \\
$\mathbf{T}_{\mathbf{3}}$ & $91.1 \pm 5.23^{\mathrm{a}}$ & $324.2 \pm 25.01^{\mathrm{a}}$ & $710.6 \pm 60.20^{\mathrm{ab}}$ & $1346.0 \pm 83.54^{\mathrm{b}}$ & $1763.6 \pm 141.37^{\mathrm{a}}$ \\
$\mathbf{T}_{\mathbf{4}}$ & $92.2 \pm 4.05^{\mathrm{a}}$ & $309.4 \pm 23.33^{\mathrm{a}}$ & $653.1 \pm 49.10^{\mathrm{a}}$ & $1169.0 \pm 87.76^{\mathrm{a}}$ & $1565.4 \pm 161.25^{\mathrm{a}}$ \\
\hline
\end{tabular}

Values with different superscripts in the same row differ significantly $(\mathrm{P}<0.05)$.

The significant effect of NLP on FCR of broiler was in close agreement with Khatun et al., (2013); Neem, nishyinda, tulsi and turmeric extract (Alam et al., 2014); Neem leaf and ginger extract (Rahman et al., 2015); Neem, turmeric and papaya leaf extract (Mahejabin et al., 2015). Growth effects of neem and antibiotic treatment without significant difference in the present study could be explained by the findings of Ansari et al. (2012), who reported that the growth properties of NLE depend on the concentration and dose-response relationship

\subsubsection{FCR of birds}

FCR was calculated in day 35 where best FCR was found in T3 group at $35^{\text {th }}$ day, followed by $\mathrm{T} 1$, T1 and lees feed conversion was observed in $\mathrm{T} 4$ group.

Table 2. Feed Conversion Ratio (FCR) of birds at day 35 .

\begin{tabular}{cl}
\hline Groups & Feed Conversion Ratio $(\mathbf{F C R})$ \\
\hline $\mathbf{T}_{\mathbf{1}}$ & 1.68 \\
$\mathbf{T}_{\mathbf{2}}$ & 1.70 \\
$\mathbf{T}_{\mathbf{3}}$ & 1.65 \\
$\mathbf{T}_{\mathbf{4}}$ & 1.87 \\
\hline
\end{tabular}

Significant $(\mathrm{P}<0.05)$ difference were revealed for FCR in all the treatments from 7 days to 35 days of age. Poor FCR was observed in control group and better FCR was observed in T3 group.

The observation of FCR in our study is also consistent with the previous data Pagrut et al. (2018). Neem leaves have individual bioactive compounds that can be attributed to the antimicrobial and antiprotozoal properties which can limit the growth and colonization of pathogenic and nonpathogenic bacterial species in chickens gastrointestinal tract (Shivarkar et al., 2018). Thus, poultry gut could lead to greater digestion efficiency and feed utilization that resulted in improved FCR.

\subsubsection{Dressed weight}

After dressing of each bird at day 35, they were individually weighted. Among the groups $T_{3}$ and $T_{1}$ obtained highest dressed weight followed by $\mathrm{T}_{2}$ and lowest dressed weight was in $\mathrm{T}_{4}$ group (Table 3 ). 
Table 3. Dressed weight of birds after dressing at day 35.

\begin{tabular}{ll}
\hline Group & Weight of dressed birds $(\mathbf{g})$ \\
\hline $\mathbf{T}_{\mathbf{1}}$ & $1110.43 \pm 102.17^{\mathrm{ab}}$ \\
$\mathbf{T}_{\mathbf{2}}$ & $1077.38 \pm 111.32^{\mathrm{a}}$ \\
$\mathbf{T}_{\mathbf{3}}$ & $1147.10 \pm 112.54^{\mathrm{ab}}$ \\
$\mathbf{T}_{\mathbf{4}}$ & $987.63 \pm 117.32^{\mathrm{ab}}$ \\
\hline *Different letters denotes significant variation among the groups
\end{tabular}

The dressing percentage was upgraded in birds fed on neem and antibiotics, which is in line with the findings of Ansari et al. (2012), who found better dressing percentages in birds fed with herbal plant diets than control. In contrast, Paul et al. (2020) found no effects of neem extracts on carcass characteristics.

\subsection{Offal's weight of birds}

Individual bird's liver, gizzard, hear, spleen and pancreas weight was taken and no statistical significance was observed $(\mathrm{P}<0.05)$ as shown in Table 4.

Table 4. Offal's weight of birds after dressing at day 35.

\begin{tabular}{llllll}
\hline Groups & \multicolumn{5}{c}{ Offal's weight of birds (gm.) } \\
\cline { 2 - 6 } & Liver & Gizzard & Heart & Spleen & Pancreas \\
\hline $\mathbf{T}_{\mathbf{1}}$ & $49.64 \pm 0.63^{\mathrm{a}}$ & $9.17 \pm 1.02^{\mathrm{a}}$ & $20.55 \pm 2.66^{\mathrm{a}}$ & $3.58 \pm 0.31^{\mathrm{ab}}$ & $2.54 \pm 0.33^{\mathrm{a}}$ \\
$\mathbf{T}_{\mathbf{2}}$ & $57.66 \pm 0.65^{\mathrm{c}}$ & $9.62 \pm 1.03^{\mathrm{a}}$ & $22.31 \pm 2.57^{\mathrm{ab}}$ & $3.36 \pm 0.32^{\mathrm{ab}}$ & $2.59 \pm 0.23^{\mathrm{a}}$ \\
$\mathbf{T}_{\mathbf{3}}$ & $53.61 \pm 0.64^{\mathrm{a}}$ & $10.01 \pm 1.03^{\mathrm{a}}$ & $20.34 \pm 2.57^{\mathrm{a}}$ & $3.32 \pm 0.32^{\mathrm{a}}$ & $2.52 \pm 0.15^{\mathrm{a}}$ \\
$\mathbf{T}_{\mathbf{4}}$ & $48.52 \pm 0.67^{\mathrm{b}}$ & $10.42 \pm 1.02^{\mathrm{a}}$ & $19.37 \pm 2.52^{\mathrm{a}}$ & $3.53 \pm 0.31^{\mathrm{ab}}$ & $2.32 \pm 0.21^{\mathrm{a}}$ \\
\hline
\end{tabular}

*Different letters denotes significant variation among the groups

The results indicated no significant differences $(\mathrm{P}<0.05)$ between all treatment groups in offal's (liver, gizzard, heart, spleen and pancreas) weight of bird.

\section{Conclusions}

This study has shown that neem extract inclusion in water for growing broiler birds has no detrimental effect on birds which implies that their consumable products will pose no health hazard to consumers. Judging from the results of this present work corroborated with the works of other scholars in the field it is recommended that a safe level of neem extract will do no harm and can be incorporated. We therefore conclude that $3 \mathrm{gm}$ of Neem extract in their drinking water growing broiler birds encourages healthy growth and may serve as supplements for antibiotics, especially when birds are raised in areas with minimal access to veterinary service.

\section{Conflict of interest}

None to declare.

\section{References}

Agarwal DP, 2002. Biological activities and medicinal properties of neem (Azadirachta indica). Curr. Sci., 82: $1336-1345$

Alam MD, J Uddin, MA Alam, MTD Akter, MIZ Moni, F Alom, A Rahman and MAA Noman, 2014. Broiler production by using polyherbal medication (neem, nishyinda, tulsi and turmeric extract). International Journal of Innovation and Applied Studies, 9: 1161-1175.

Ansari J, SH Khan, AU Haq and M Yousaf, 2012. Effect of the levels of Azadirachta indica dried leaf meal as phytogenic feed additive on the growth performance and haemato-biochemical parameters in broiler chicks. J. Appl. Anim. Res., 40: 336-345.

Cardozo PW, S Calsamiglia, A Ferret and C Kamel, 2004. Effect of natural plant extracts on ruminal protein degradation and fermentation profiles in continuous culture. J. Anim. Sci., 82: 3230-3236.

Guo FC, 2003. Mushroom and herb polysaccharides as alternative for antimicrobial growth promoters in poultry. PhD Thesis. Wageningen University, Netherlands. 
Islam MK, SML Kabir, A Haque, YA Sarker and MH Sikder 2018. Molecular detection and characterization of Escherichia coli, Salmonella spp. and Campylobacter spp. isolated from broiler meat in Jamalpur, Tangail, Netrokona and Kishoreganj districts of Bangladesh. Afr. J. Microbiol. Res., 12: 761-770.

Jawad Z, M Younus, MU Rehman, R Munir, A Maqbool, W Shahzad, S Masood and K Muhammad. 2014. Effect of Azadirachta indica on the hepato-renal functions in broilers chickens. J. Anim. Plant Sci., 24:10121018.

Khatun S, M Mostofa, F Alom, J Uddin, MN Alam and NF Moitry, 2013. Efficacy of tulsi and neem leaves extract in broiler production. Bangl. J. Vet. Med., 11: 1-5.

Mahejabin N, M Mostofa, F Akter, S Das and M Alam, 2015. Effects of Neem, turmeric and papaya leaf extract mixture on growth performance of broilers. Int. J. Nat. Soc. Sci., 2: 17-21.

Noman ZA, MM Hasan, S Talukder, YA Sarker, TK Paul and MH Sikder, 2015. Effects of garlic extract on growth, carcass characteristics and haematological parameters in broilers. The Bangladesh Veterinarian, 32: $1-6$.

Pagrut N, S Ganguly, S Tekam, and P Bhainsare, 2018. Effects of neem leaf infusion supplementation as a growth promoter in the diet of broiler chicks. J. Entomol. Zool. Stud., 6: 249-250.

Paul TK, MM Hasan, MA Haque, S Talukder, YA Sarker, MH Sikder, MAHNA Khan, MN Sakib and A Kumar, 2020. Dietary supplementation of Neem (Azadirachta indica) leaf extracts improved growth performance and reduced production cost in broilers. Vet. World, 13: 1050-1055.

Rahman MA, MA Ali, BK Saha, MA Hasan, MA Rahman and M Mostofa, 2015. Use of neem leaf and ginger extracts for cost effective broiler production. Int. J. Nat. Soc. Sci., 2: 11-16.

Sarker YA, MM Hasan, TK Paul, SZ Rashid, MN Alam and MH Sikder, 2018. Screening of antibiotic residues in chicken meat in Bangladesh by thin layer chromatography. J. Adv. Vet. Anim. Res., 5: 140-145.

Sarker YA, SZ Rashid, S Sachi, J Ferdous, BL Das Chowdhury, SS Tarannum and MH Sikder, 2020. Exposure pathways and ecological risk assessment of common veterinary antibiotics in the environment through poultry litter in Bangladesh. J. Environ. Sci. Health B, 55: 1061-1068.

Shivarkar R and QR Code, 2018. HPTLC fingerprinting and antimicrobial activity of Azadirachta indica leaf extracts. Int. J. Biomed. Adv. Res., 9: 235-240.

Subapriya R and S Nagini, 2005. Medicinal properties of neem leaves: a review. Curr. Med. Chem. Anticancer Agents, 5: 149-156.

Talukder S, MM Hasan, ZA Noman, YA Sarker, TK Paul and MH Sikder, 2017. Effect of dietary supplementation of ginger extract on growth, carcass characteristics and haematological parameters in broilers. Asian J. Med. Biol. Res., 3: 211-215. 